\title{
Artificial maintenance of the relative ocular tissue pressure during eye surgery
}

\author{
C Maggi, R Maggi
}

\begin{abstract}
We describe an operating table in which the whole patient, apart from the eye undergoing surgery, is enclosed in a caisson within which the barometric pressure can be lowered at any time during surgery. This increases the effect of atmospheric pressure on the eye, enabling 'open sky' surgery to be carried out on patients of any age.
\end{abstract}

In mammals the rigidly enclosed organs such as the eyeball or the brain have their tissue pressure maintained by the fixed volume of the enclosed liquids which are in constant balance with the pressure of the vascular network. This balance is controlled by a blood-brain or blood-aqueous barrier, ' in accordance with the law of MonroKellie. ${ }^{2}$ Any sudden change in volume of the liquids, such as during surgery, disrupts this balance of pressure across the vascular walls and subverts the dynamics of the local blood circulation. ${ }^{3}$

The eyeball is enclosed in the bony cavity of the orbit, open only to the exterior. By separating the operating field, including the eye, by a rigid

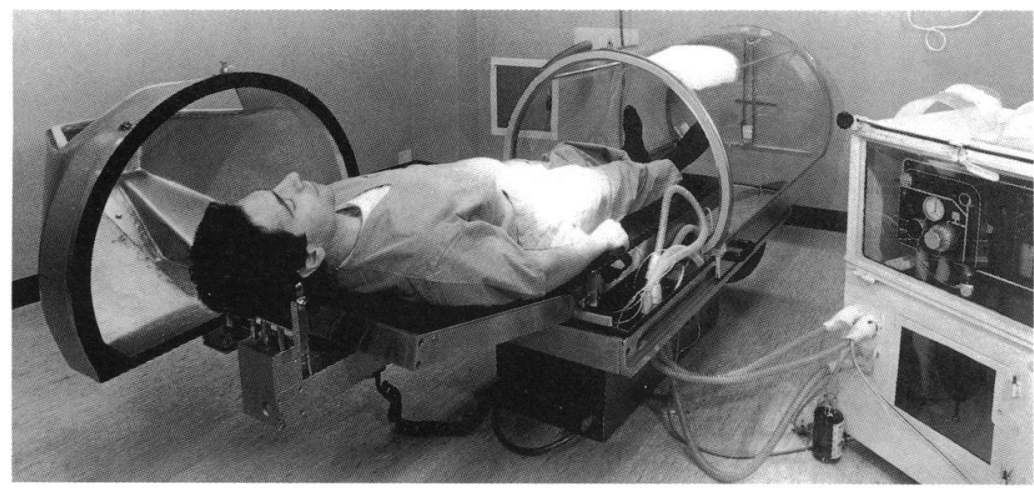

Figure 1A

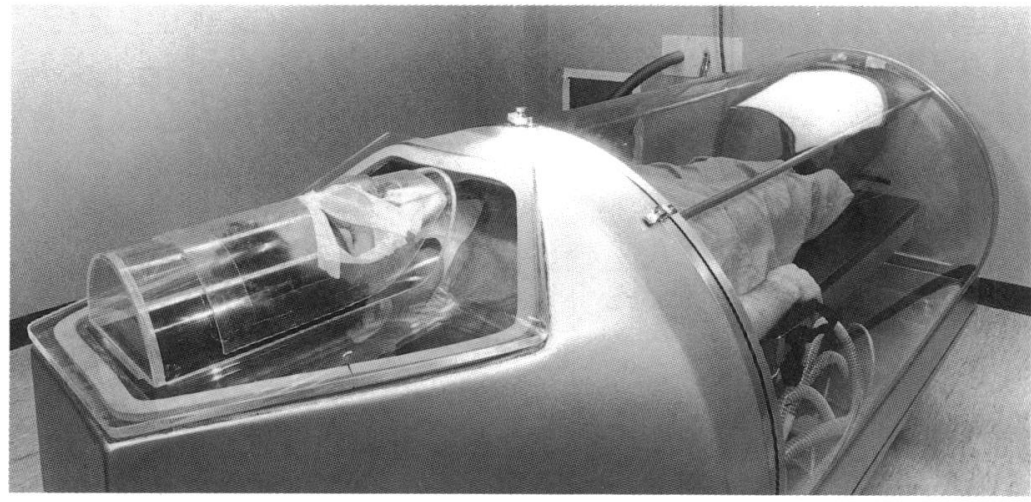

Figure $1 B$

Figure 1: The operating table before $(A)$ and after $(B)$ airtight closure. Note the sealed container for the pulmonary ventilator, which is in communication with the caisson to maintain the same ambient pressure. adhesive membrane from the rest of the body which is enclosed in a caisson (similar to a hyperbaric chamber) a difference in pressure can be regulated on both sides of the separation, either by increasing the atmospheric pressure in the room, ${ }^{4}$ or by decreasing the atmospheric pressure on the patient's respiratory system. We describe a new device for raising the relative atmospheric pressure on the contents of the eye during surgery.

\section{Materials and methods}

The patient is enclosed in an airproof container (caisson), and the orbital rim is sealed to a hole suitably situated in it (Fig 1A, 1B). With a vacuum pump the environmental pressure inside the airtight container is decreased by $15 \mathrm{mmHg}$ that is the average intraocular pressure. On the eye being opened the loss of aqueous causes a fall of the intraocular pressure to the level of that existing on the exterior of the caisson.

In these conditions the loss of the liquid volume of the eye removes any influence on the haemodynamics of the eye, which is now directly influenced by the relative compression resulting from the difference in pressure on the inside and outside of the caisson, and monitored by the suction pump. A normal turnover of the aqueous in the leaking eye allows safe open-sky surgery for any length of time desired.

If the vena cava pressure is monitored in the proximity of the right atrium when the pressure inside the caisson is decreased, a parallel change in the central venous pressure from positive to negative is found to take place. There is invariably a clearly visible sinking of the eye in the orbit, which is now depleted of venous blood.

In the surgically opened eye the loss of tissue pressure against the thin walls of the choroidal veins is now balanced by the negative pressure already established in the vena cava, and no increase in the venous volume of the choroid occurs. In the same way, on the arterial side, the normal difference in pressure between the left ventricle and the intraocular capillaries is equally maintained, as the lowering of the peripheral resistance following the opening of the eye is balanced by a parallel decrease in the absolute pressure of the left ventricle. The blood pressure, if measured inside the depressurised caisson, remains unchanged, being merely relative to the patient's atmospheric pressure. Thus a normal gradient of pressure is reestablished on both the arterial and the venous side of the intraocular capillary network in spite of the sclera being open. Normal anaesthetic monitoring and safety can be maintained by the caisson.

A safety valve in the caisson is regulated at a 
pressure of $40 \mathrm{~cm}$ of water, preventing an inadvertent excessive decrease in the ambient pressure on the patient's body. In any emergency the pump is stopped and the interior pressure returns to normal within three seconds. This allows manual opening of the cover and free access to the patient's body but leaves the sterile surgical field undisturbed. In general anaesthesia a pulmonary ventilator is used. This is enclosed in an airproof container at the same pressure as that acting on the patient's body (Fig 1A).

In conventional eye surgery when the sclera is opened several undesirable consequences occur: in the valveless intraocular veins the blood outflow (which relies on the tissue pressure ${ }^{5}$ ) comes to a standstill, and venous engorgement follows. The thin walled veins, distended by the blood pooling, start leaking plasmoid fluid, upsetting the blood-aqueous barrier and causing stagnation in the subchoroidal space. ${ }^{67}$ The resulting increase in the volume of the choroid progressively reduces the space available for the vitreous body, which in a long operation may bulge forward. In elderly patients the early loss of aqueous from the mostly liquefied vitreous gel makes more room for the swollen choroid, ${ }^{810}$ and positive vitreous pressure becomes less noticeable in brief open-sky surgery. In babies and young patients, who have high scleral elasticity and a dense vitreous, scleral retraction and consequent vitreous prolapse soon follow. In these patients the wide limbal opening used in adults is considerably less safe.

The development of these events is prevented by the peroperative use of our technique, and open-sky surgery of any length can be safely performed in all patients, of any age or eye condition.

\section{Results}

Although this special operating table has been routinely used in all kinds of intraocular surgery, intracapsular cataract extraction in children is reported on in Table I as an example of open-sky surgery made possible with this technique. In none of these cases did intraoperative vitreous pressure occur. A small loss of vitreous occurred in six of the first cases as a result of an error in technique (undue pressure on the eyeball from the exterior) but did not cause late complications. Postoperative glaucoma occurred in two eyes after operation for traumatic cataract and needed surgery. A disinsertion of the retina occurred in

TABLE I Intracapsular extraction

\begin{tabular}{|c|c|c|c|c|c|}
\hline \multirow[b]{2}{*}{ Age } & \multicolumn{4}{|l|}{ Year } & \multirow[b]{2}{*}{ Total } \\
\hline & $\begin{array}{l}1-6 \\
\text { months }\end{array}$ & $\begin{array}{l}7-11 \\
\text { months }\end{array}$ & $\begin{array}{l}1-3 \\
\text { years }\end{array}$ & $\begin{array}{l}4-12 \\
\text { years }\end{array}$ & \\
\hline 1979 & - & 1 & 1 & _- & 2 \\
\hline 1980 & - & - & 1 & 2 & 3 \\
\hline 1981 & 3 & 2 & 1 & 2 & 8 \\
\hline 1982 & 1 & 4 & 4 & 5 & 14 \\
\hline 1983 & 1 & 10 & 5 & 6 & 22 \\
\hline 1984 & - & - & 3 & 6 & 9 \\
\hline 1985 & 2 & 3 & 2 & 5 & 12 \\
\hline 1986 & 2 & 2 & 4 & 3 & 11 \\
\hline 1987 & 7 & 1 & 4 & 7 & 19 \\
\hline 1988 & 2 & 5 & 2 & 1 & 10 \\
\hline Total & 18 & 28 & 27 & 37 & 110 \\
\hline
\end{tabular}

The earliest intracapsular extraction took place at the age of 1 month. In $42 \%$ of the 110 cases the operation was performed during the first year of life. one case of unilateral cataract three years after surgery.

In all cases the operation was carried out without any specific manoeuvres to prevent vitreous pressure such as the use of an eye compressor, hyperosmotic or hypotensive agents, or a scleral ring.

\section{Discussion}

This method, in 10 years' experience, has offered the following advantages.

Control of the vitreous pressure. The compression of the ocular contents greatly accelerates vitreous dehydration, already started by the opening of the scleral coat. ${ }^{9}$ The dehydrated vitreous body is uniformly pressed against the scleral wall, compressing the choroid and preventing swelling. Vitreous loss becomes practically impossible even in the absence of the posterior capsule. If, after accidental external pressure, the vitreous undergoes prolapse, it can easily be repositioned with a spatula, because of the inverted vitreous pressure.

Peroperative hypotony. Once the pump is functioning, hypotony is immediately noted. Hyperbarism of $20 \mathrm{~cm}$ of water, the equivalent of intraocular pressure, is sufficient to achieve this result. Greater hypotony is available by further lowering the patient's environmental pressure in the caisson. No damage is possible from hypoxia, because the maximum relative orbital hyperbarism allowed by the pump is lower than the systolic pressure of the retinal arteries. If surgery is started at normal atmospheric pressure, and vitreous is under pressure, an immediate relative hypotony can be obtained merely by switching on the pump.

Intraocular space during surgery. A continuous flow of aqueous, in part normally produced and in part squeezed from the vitreous, maintains some depth of the anterior chamber, at least sufficient to prevent contact with the cornea during intraocular lens implantation. The anterior chamber can easily be kept full of air.

Because of the preserved blood-aqueous barrier during surgery very little aqueous flare can be noted postoperatively, and the routine use of mydriatics has proved unnecessary. Deposits on the implant have not been observed after surgery under hyperbarism.

The likelihood of retinal detachment, a frequent occurence in aphakic children, ${ }^{11}$ is probably reduced by the lack of intraoperative forward displacement of the vitreous body due to the hyperbarism.

CONCLUSION

We propose that relative pneumatic hyperbaric compression of the eye during surgery, by means of the caisson operating table, maintains a normal intraocular pressure on the vascular network independently of the liquid volume of the eye, preventing choroidal swelling. Aqueous turnover and the blood-aqueous barrier are undisturbed during surgery. With the use of this technique an alternative to closed surgery is proposed with the aim of avoiding any disturbance to the anatomy of the eye. 
In adult patients the avoidance of precautional hypotensive treatment and the immediate and harmless effect of hyperbarism on the eye soon come to be preferred by both the surgeon and the anaesthetist, once they become acquainted with the slight differences imposed by the new technique. In implant surgery the assurance of the intraocular spaces being maintained increases the confidence of the surgeon.

1 Kuriowa T, Cahn R, Huhler M, et al. Role of extra-cellular proteins in the dynamics of vasogenic brain edema. Acto Neuropathol (Berl) 1978; 66: 3-11.
2 Brotch J. Les oedèmes cérébraux neurochirurgicaux; méchamisme d'incidence thérapeutique. Rev Med Brux 1986; 7: 217-9.

- 3 Maggi C. L'iperbarismo settoriale in chiurgia oculistica. Boll Oculist 1985; 65: 335-41.

4 Maggi C. Eye surgery in a new hyperbaric room. Ophthalmol Proc 1978; series 21: 347-57.

5 Brubacker RF. Editorial. Arch Ophthalmol 1984; 102: 1753-4.

6 Jaffe N. Cataract surgery and its complications. St Louis: Mosby,

7 Schepens CL. Clinical and research aspects of subtotal openSchepens CL. Clinical and research aspects of subto
sky vitrectomy. Am J Ophthalmol 1981; 91: 143-9.

8 Robbins R, Galin MA. Effects of osmotic agents on the vitreous body. Arch Ophthalmol 1969; 82: 694-9.

9 Robbins RM, Obstbaum SA, Galin MA. Intraocular pressure rebound. Brf Ophthalmol 1971; 55: 177-82.

10 Brubaker RF, Riley FC. Vitreous body reduction in the rabbit. Arch Ophthalmol 1972; 87: 438-42.

11 Roussos J, Polychroniadis F. La décollement de la rétine suite à l'extraction de la cataracte. Ann Oculist (Paris) 1973; 206: 315-9. 